oster session II

\title{
Reaction sequence of thin Ni films with (001) 3C-SiC
}

\author{
S.M. Gasser - A. Bachli' - E. Kolawa - M.A. Nicolet \\ California Institute of Technology, Pasadena/Ca 91125 (USA) \\ Tel. : +1 (818) 395-6555-Fax : +1 (818) 395-2944-E-mail : sgasser@cco.caltech.edu \\ 'current address : Balzers. AG, Iramali 18, 9496 Balzers (Liechtenstein)
}

Nickel is frequently used as a contact to $\mathrm{SiC}$. We investigate the reaction sequence between $\mathrm{Ni}$ and cubic $\mathrm{SiC}$ at annealing temperatures between $400^{\circ} \mathrm{C}$ and $700^{\circ} \mathrm{C}$ in vacuum.

The films are analyzed by $3.2 \mathrm{MeV}^{4} \mathrm{He}^{++}$backscattering spectrometry and secondary ion mass spectrometry to determine elemental depth profiles, X-ray diffraction to characterize reaction compounds, and cross sectional transmission electron microscopy to visualize the microstructure of the reacted layer.

We find that a reaction starts after annealing at $450^{\circ} \mathrm{C}$ for 30 min with an outdiffusion of carbon through the nickel layer up to the surface where it remains stable during additional annealing.

The same annealing temperature leads to interdiffusion of $\mathrm{Ni}$ and $\mathrm{Si}$ with formation of the $\mathrm{Ni}_{3} \mathrm{Si}$ phase. $\mathrm{Ni}_{31} \mathrm{Si}_{12}$ starts to form at $450^{\circ} \mathrm{C}$ after annealing during $120 \mathrm{~min}$, and it is the only detected phase in the sample annealed at $500 \mathrm{C}$. The $\mathrm{Ni}_{2} \mathrm{Si}$ phase, which is the thermodynamically stable phase with $\mathrm{SiC}$ together with elemental $\mathrm{C}$, starts to grow down from the surface toward the $\mathrm{SiC}$ at $600^{\circ} \mathrm{C}$, and about half of the previous layer is consumed after $30 \mathrm{~min}$. After the $700^{\circ} \mathrm{C} / 30 \mathrm{~min}$ anneal only this phase can be detected. At this stage, the carbon distribution still shows an accumulation on the surface, followed by a concentration sink underneath and an almost constant distribution through. most of the remaining depth of $\mathrm{Ni}_{2} \mathrm{Si}$ down to the interface. In terms of the microstructure the film shows two major distinct layers, an upper part with very fine structure, and a lower part of distinctly columnar structure.

\$M'97 - Materials for Avanced Metallization 